Linguagens, Educação e Sociedade, Teresina, Ano 22, n. 37, jul./dez. 2017

Revista do Programa de Pós- Graduação em Educação da UFPI| ISSN 1518-0743

\title{
A CRIANÇA COM TRANSTORNO OPOSITIVO DESAFIADOR NAS AULAS DE EDUCAÇÃO FÍSICA: PRESSUPOSTOS INCLUSIVOS
}

\section{FABIANA ZANOL ARAÚJO}

Especialista em Treinamento Desportivo, musculação e Personal Training, licenciada em Educação Física. Professora de Educação Física da Prefeitura Municipal de Vitória. Integrante do grupo de estudo e pesquisa em Educação e Inclusão - GEPEI - Universidade Federal do Espírito Santo.

E-mail: fabianzanol@terra.com.br

MICHELL PEDRUZZI MENDES ARAÚJO

Mestre em Educação pela Universidade Federal de Espírito Santo, na linha de Diversidade e Práticas Educacionais Inclusivas, especialista em Educação Inclusiva pelo ISECUB e em Gestão Escolar pela Faculdade Afonso Cláudios/ES. Licenciada em Ciências Biológicas pela Universidade Federal do Espírito Santo. Professor de Biologia e de Ciências na SEDU do Estado do Espírito Santo. Integrante do grupo de estudo e pesquisa em Educação e Inclusão - GEPEI Universidade Federal do Espírito Santo. E-mail: michellpedruzzi@ yahoo.com.br

\section{RESUMO}

O Transtorno Opositivo Desafiador é caracterizado por comportamentos de negação, desafiadores, desobedientes e hostis para com figuras de autoridade. Em geral, as crianças começam a apresentar as características no início da infância, época em que esses comportamentos são esperados. Por isso, há a necessidade de se avaliar em que situações esses comportamentos ocorrem, a intensidade e prejuízo que geram a fim de distinguir esse transtorno dos desafios normais da idade. Tendo em vista a complexidade do transtorno supracitado e a presença de um aluno com o mesmo em uma escola de ensino comum do município de Vitória-ES, na qual trabalhamos, resolvemos fazer este estudo que tem como objetivo central trazer à tona o processo de inclusão do indivíduo com esse transtorno nas aulas de educação física. Para atingir o objetivo exposto, recorremos à metodologia pesquisa-ação porque essa metodologia se constitui como um instrumento importante para colocar em colaboração o praticante e o pesquisador na implementação de ações didádico-pedagógicas. Para a produção de dados, utilizamos a observação participante e, para a interpretação deles, recorremos aos pressupostos da perspectiva sócio-histórica de Vigotski e de seus colaboradores. Como resultados desse trabalho, ressaltamos a necessidade de propostas metodológicas para o trabalho pedagógico com a criança com esse transtorno, onde cada criança é singular. Por isso, nós professores devemos observar quais atividades a criança aprecia realizar dentro do contexto escolar, assim, o contexto social e cultural do sujeito será valorizado e as características biológicas serão deixadas em segundo plano.

PALAVRAS-CHAVE: Inclusão. Transtorno Opositivo Desafiador. Educação Física. 


\begin{abstract}
The Oppositional Defiant Disorder is characterized by behaviors of denial, defiant, disobedient and hostile toward authority figures. In general, the children begin to exhibit characteristics as any early childhood, whose behaviors are expected within this period. Therefore, it is necessary to assess situations, which occur an intensity and prejudice that generate an end to distinguish this disorder of normal challenges age. It has given the complexity of the aforementioned disorder as an attendance student with the same in a common Education School in the city of Vitória-ES, where we work. We decided to do this study whose main goal is to bring out the inclusion process of that individual with disorder as a participant in Physical Education lessons. In order to achieve suggested goals, we used the methodology for Action Research Methodology, which constitutes an important instrument that put together researcher and practitioner in didactic-Pedagogical actions implementation. Data Production used as a semi-structured interview, Participant Observation and Interpretation Peer to them, which resorted assumptions of Social-Historical Perspective of Vygotsky and his collaborators. As a result of this work, we emphasize the need for paragraph methodological proposals, the pedagogical work with a child with this disorder, and the fact that every child is unique. So, we should note teachers activities what a child appreciates conduct within the school context, thus the social, cultural and subject will be, and valued as biological characteristics will be left Background.
\end{abstract}

KEYWORDS: Inclusion. Oppositional Defiant Disorder. Physical Education.

\title{
INTRODUÇÃO
}

A inclusão dos alunos com deficiência, transtornos globais do desenvolvimento e altas habilidades na escola comum está assegurada legalmente, de modo que, hoje não é o aluno que está obrigado a se adaptar à escola, mas a escola tem que se organizar para recebê-lo. Para Sobrinho (2003, p. 12), “Incluir é fazer parte, é compreender, é ser compreendido”. Uricoecha (2005) diz que inclusão é o termo que se encontrou para definir uma sociedade que considera todos os seus membros como cidadãos legítimos. Inclusão significa, entre tantas coisas, "estar com", compreensão, envolvimento, mudança de postura, ou seja, traduzem-se em mobilizar pais, estudantes, membros da comunidade para ser parte de uma nova cultura, de uma nova realidade. E um contexto de educação inclusiva, acontece, com a tentativa e esforço de se desenvolver um sistema educacional unificado que seja flexível e que tenha recursos necessários para atender às necessidades dos alunos.

Após muitos anos de discriminação, marginalização e até mesmo eliminação de indivíduos com deficiência, por meio de iniciativas racistas e eugênicas, é difícil que o processo de 
sensibilização e aceitação das diferenças ocorra de imediato. É o que percebemos no processo de inclusão de um aluno com transtorno opositivo desafiador nas aulas de educação física, onde normalmente nessas aulas objetiva-se a padronização de movimentos e a aceitação de regras impostas. Sob esse prisma, é importante ressaltar que vivemos em uma sociedade pensada e projetada para um homem padrão, próximo à normalidade, que, não corresponde à verdadeira condição da maioria da população. Um padrão que se utiliza da diferença para inferiorizar e da igualdade para descaracterizar. O que tem tornado a inclusão um processo complexo e lento, embora tenhamos um aumento de alunos com deficiência nas escolas.

Segundo Victor; Drago; Pantaleão (2013) e Carmo (2002), esse crescimento inclusivo nas escolas, tem deixado professores e gestores confusos ou tendo que buscar, cada vez mais, respostas de como atender no mesmo espaço - tempo crianças que apresentam diferentes habilidades, diferentes comportamentos e diferentes histórias de vida. Estamos falando das diferenças concretas existentes entre os homens, que sempre existiram, porém foram negadas ou desconsideradas pela maioria dos educadores.

Nesse sentido, o presente trabalho tem como principal objetivo trazer à tona o processo de inclusão de um aluno com transtorno opositivo desafiador ( $\mathrm{TOD}^{1}$ ) nas aulas de educação física. Sendo esse um transtorno psicossocial recente e pouco conhecido, fez com que o interesse sobre o tema aumentasse e começássemos então, a pesquisar mais sobre o assunto. Com base na experiência diária e nas leituras sobre o assunto, percebemos a complexidade do processo de inclusão escolar de um aluno com TOD, pois esse processo não se resume em seguir uma receita ou manual, mas é algo que é construído por meio da vivência com a criança no espaço escolar.

De forma a atingir o objetivo supracitado, recorremos à metodologia pesquisa-ação (ABREU, 2011). Isso porque entendemos que a pesquisa-ação se constitui como um instrumento metodológico importante para colocar em colaboração o praticante e o pesquisador na implementação de ações didádico-pedagógicas, que possam fazer frente ao processo de inclusão de crianças com TOD nas aulas de Educação Física.

É importante antever que o presente trabalho se justifica para gestar a oportunidade de contribuir para o avanço qualitativo do ensino, fornecendo-se subsídios para uma reflexão desse transtorno e a inclusão na Educação Física Escolar. Nesse caminho, escolhemos fazer uma pesquisa qualitativa, com uma abordagem sócio-histórica, baseando-nos nos conceitos de Vigotski e de outros autores que imprimem em seus textos raízes sócio-históricas. Procuramos então,

\footnotetext{
${ }^{1}$ Utilizaremos a sigla TOD para nos referirmos ao Transtorno Opositivo Desafiador.
} 
problematizar e discutir como fazer com que a criança opositora participe das aulas de educação física, respeitando as regras e se apropriando da cultura corporal de movimento.

Iniciaremos o presente texto com a definição de transtorno opositivo desafiador (TOD), tendo em vista os aspectos genotípicos e fenotípicos. Traremos também a proposta metodológica do estudo e suas implicações teóricas. Em seguida, dissertaremos acerca da inclusão do indivíduo com esse transtorno nas aulas de Educação Física, considerando o ser humano em suas dimensões biológica, social e cultural. Por fim, traremos à tona algumas tecituras acerca da inclusão dos sujeitos com esse transtorno a âmbito da escola comum.

\section{TRANSTORNO OPOSITIVO DESAFIADOR: UMA BREVE DISCUSSÃO TEÓRICA}

O Transtorno Opositivo Desafiador (TOD) consiste em um transtorno psicológico caracterizado, principalmente, por comportamentos apresentados pela criança no sentido de agir contrariamente àquilo que se pede ou se espera dela. Diferentes comportamentos caracterizam o problema: Segundo Kaplan et al. (2003, p.995, grifo do autor), “o Transtorno opositivo desafiador consiste em um padrão persistente de comportamentos negativistas, hostis e desafiadores na ausência de sérias violações de normas sociais ou direitos alheios".

Crianças agressivas, que desafiam pais e professores, discutem, não aceitam regras e às vezes, com mau desempenho na escola, tem se tornado cada vez mais comum, e é preciso prestar muita atenção a esses casos de desobediência porque eles podem se agravar e se transformar no transtorno opositivo desafiador.

A família precisa se preocupar quando esse padrão de comportamento citado se torna um padrão comum. Nesse caso, a criança nunca cede e se recusa a entrar em acordo normalmente com todos que o rodeiam, logo se a criança não se submete as regras, a parceria fica comprometida. É importante dizer que desafiar os pais e os professores até certo ponto é considerado saudável no desenvolvimento da criança na infância, mas o desafiar deliberado significa que tem algo que precisar ser avaliado. O diagnóstico precisa ser feito considerando o prejuízo real no cotidiano nas suas interações e faltas delas no social.

Em qualquer parte do mundo, e em qualquer cultura, existem crianças com comportamentos diferentes. O que devemos observar é quando determinado comportamento começa a trazer prejuízos para a criança, ainda que haja uma subjetividade em dizer o que é prejuízo. Se a oposição e o desafio começam a acontecer com muita frequência, essa criança começa a ficar prejudicada na 
questão dos relacionamentos, por exemplo, na família, na escola ou com outras figuras de autoridade.

O comportamento opositor desafiador consiste em um transtorno psicológico caracterizado principalmente aos comportamentos negativistas apresentados pela criança normalmente em todas as suas relações, seja no espaço escolar ou/e familiar em geral para com as figuras de autoridade (Mãe, pai, professora, tios). Segundo Mondoni e Pitliuk (2010, p. 4):

O TOD se caracteriza por um padrão recorrente de comportamentos que tendem ao desafio, à desobediência, à provocação e ao negativismo ou oposição. Estes comportamentos são em geral dirigidos a figuras de autoridade, mas de qualquer forma se encontram disseminados em todos os círculos sociais do indivíduo.

As características do TOD variam de acordo com a idade da criança e a gravidade do transtorno. O critério de gravidade desse transtorno se caracteriza em quantos ambientes as crianças apresentam essas características. Se apenas no ambiente familiar, e/ou na escola, ou em todos os ambientes que ela frequenta, esta seria com maior gravidade. A causa do TOD em crianças é avaliada por questões familiares como conflitos na relação familiar ou discórdia conjugal, e fatores genéticos associados a desencadeadores ambientais. Além disso, outros estudos sugerem que mães com transtorno depressivo estão com maior probabilidade de ter uma criança que possa desenvolver o TOD (RELVAS, 2010).

Bater, ofender, liderar um grupo contra colegas, quase sempre esta atitude tem uma causa familiar. É verdade que cada criança possui conteúdos genéticos, psíquicos próprios, mas a família e o ambiental em que vive são responsáveis por grande parte deste comportamento. Pais agressivos ou tolerantes em excesso, pais com alto grau de exigência ou em desacordo com o modo de educar, pais superprotetores e com medo de corrigir geram comportamentos agressivos. Em crianças com uma vulnerabilidade genética vindo de um transtorno secundário, como por exemplo, o Transtorno de Déficit de Atenção e Hiperatividade (TDAH), geralmente o desfecho mais provável é a oposição e o desafio.

Em relação aos vários procedimentos de tratamento para TOD, autores referem-se a diferentes estratégias como: O tratamento primário para o TOD consiste em uma psicoterapia individual para a criança, com aconselhamento e treinamento direto dos pais, acerca de habilidade de manejo da criança (KAPLAN, SADOCK e GREBB, 1997, p.996).

Acerca do tratamento do TOD, Teixeira $(2006$, p. 2) disserta que o procedimento medicamentoso é algo que ainda não está bem definido, pois não há nada bem específico em se tratando desse transtorno. $\mathrm{O}$ autor, entretanto, sugere que por meio de vários trabalhos científicos e muitos artigos 
estudados relatam o uso de psicofármacos ${ }^{2}$ no manejo dos sintomas opositivos desafiadores apresentados pela criança.

Vale ressaltar que, para as crianças com esse diagnóstico do TOD, é de fundamental importância o tratamento adequado o quanto antes, para assim evitar um possível risco de evolução do transtorno que, muito provavelmente, causará prejuízos significativos em seu desempenho com os seus colegas de sala de aula, professores e provavelmente no meio familiar e qualquer relação social da criança opositora.

Para Luiselli (2005), compreender as causas do TOD nas crianças é uma iniciativa complicada, pois, o TOD tem a influência de múltiplos fatores que se encontram inter-relacionados, no sentido de que podem funcionar como variáveis que atuam como causa e variáveis que atuam como efeito. Salientando que existem várias evidências de que o TOD é moldado e mantido pela natureza das trocas mútuas entre a criança e os adultos significativos de seu convívio, começando com os pais e estendendo-se a outras figuras como autoridades. Na instituição escolar o sujeito TOD desafia as autoridades, cria apelidos para os colegas enaltecendo seus possíveis defeitos e fraquezas, tendem a discutir insistentemente com o professor (a), se opõe a realização de tarefas nos momentos mais inoportunos (como por exemplo, nas avaliações), não se relaciona com os colegas, tende a isolar-se, fala compulsivamente, é ansioso, hiperativo, entre ouros comportamentos. O autor salienta que, quando se aborda as causas destes comportamentos, é apropriado levar em conta as características da criança e dos pais, assim como as variáveis (do contexto) situacionais, que podem controlar a qualidade das interações criança/adulto.

Luiselli (2005) também afirma ser provável que crianças que apresentam reações emocionais extremas, irritabilidade crônica, impulsividade e falta de atenção, tendem a desenvolver comportamentos de oposição. O mesmo autor afirma que essas respostas estão relacionadas com o temperamento infantil, o que pode estar ligado a uma base genética ou constitucional. Essas crianças que apresentam temperamento difícil não se acalmam facilmente, não se adaptam bem às mudanças ambientais e são "resmungonas". Por outro lado, segundo o autor, os principais padrões de comportamento dos pais, observados em famílias de crianças que têm um TOD são: a imaturidade, a falta de experiência com relação à educação dos filhos, a hostilidade e a habilidade emocional. Assim, a presença de conflitos conjugais, de depressão materna e de psicopatologia parental, em geral, sinaliza também um risco para o TOD. O mesmo autor ressalta que, em certo sentido, esses e outros fatores relacionados podem determinar uma tendência nos pais a se

\footnotetext{
${ }^{2}$ São substâncias químicas que alteram o comportamento, o humor, a percepção ou as funções mentais. São utilizados para tratar pacientes com distúrbios mentais. A maioria age alterando o processo de neurotransmissão. (egolegal.blogspot.com/2011/11/o-que-são-pisicofarmacos, Acesso em Agosto de 2014) .
} 
comportarem e responderem a seus filhos de forma que aumente a probabilidade de encontrarem desobediência, oposição e desafio. A identificação das características da criança e dos pais indicam a importância de compreender os intercâmbios recíprocos nas interações crianças/pais no desenvolvimento e manutenção do TOD” (LUISELLI, 2005). Além disso, o autor divide os fatores de interação pai - criança em dois níveis:

1-As habilidades parentais deficientes, como não prestar atenção a sinais significativos da criança (por exemplo, quando está claro o mal-estar), não colocar limites ao comportamento impróprio e não vigiar de forma constante o nível de atividade podem funcionar também como acontecimentos antecedentes que provoquem e mantenham o desafio (LUISELLI, 2005, p. 42).

2- As crianças com um TOD e seus pais realizam inúmeros intercâmbios interpessoais que são 'reforçados negativamente'. A pesquisa de Patterson e seus colaboradores, por exemplo, demonstra que quando as crianças atuam de maneira desafiadora, negativa e agressiva para com seus pais, tal comportamento frequentemente produz consequências favoráveis, como o fim das demandas, a retirada da atenção não desejável ou a obtenção de algo agradável (...) Como resultado, esses comportamentos são fortalecidos e ocorrerão com maior probabilidade no futuro. Do mesmo modo, quando os pais são severos, punitivos ou negativos em suas interações com a criança, às vezes são reforçados, porque esse comportamento produz obediência ou elimina uma fonte de irritação (por exemplo, a criança 'cede'). Com efeito, tanto a criança quanto os pais aprendem a realizar comportamentos negativos e coercitivos quando enfrentam acontecimentos desagradáveis ou aversivos (LUISELLI, 2005, p. 42).

Os pais e os professores devem enxergar o lado positivo dessa firmeza da criança opositiva e direcionar isso de forma a potencializar essas características visando ao melhor convívio e desempenho na família e na escola. É necessário um ambiente saudável, que se estabeleçam regras e limites com pedidos claros e objetivos. Pais e professores que ajudam essas crianças a executar e se impor no momento certo, proporcionam um fator positivo de interação.

Veremos a seguir que a aprendizagem nas aulas de educação física do sujeito opositor, em sua maioria, acontece pela emoção, muito mais pelo funcionamento das condições biológicas e orgânicas. O processo de ensino/aprendizagem flui das emoções, a empatia ou apatia com o qual esses sujeitos sentem ao experimentar algo.

\section{A PESQUISA-AÇÃO COMO PROPOSTA METODOLÓGICA}

Para entender e propiciar, efetivamente, o processo de inclusão dos sujeitos com transtorno opositivo desafiador nas aulas de educação física, optamos pela metodologia pesquisa-ação imersa em uma perspectiva histórico-cultural do desenvolvimento humano. Autores como Abreu (2011) e Chicon (2005), reconhecem a pesquisa-ação como adequada para o processo de mudanças nas práticas pedagógicas de professores de Educação Física, ao perceberem seu potencial no levantamento de demandas docentes e discentes e nos procedimentos que visam atendê-las na busca por um avanço no cotidiano escolar. Entretanto, para que os objetivos não sejam derivados, é necessário manter um planejamento com ações não necessariamente definidas, porém claras. 
Ao buscar uma compreensão acerca da inclusão dos sujeitos com deficiência, em nosso caso específico, crianças com TOD nas aulas de Educação Física, pretendemos reconhecer que os professores, mais que reprodutores de uma cultura e de um conhecimento hegemônico, são produtores ativos de conhecimento e culturas. Pretendemos, também, reconhecer as crianças com transtornos como sujeitos de direitos e produtoras de cultura, seres sociais que têm protagonismo no processo de construção/apropriação desses conhecimentos e dessas culturas. Nesse sentido, a compreensão e a pretensão delineadas anteriormente tornam-se mais possíveis com a utilização da metodologia pesquisa-ação, quando permite que o professor (re)pense a sua própria práxis.

Compreendemos, portanto, que o processo de aprendizagem nas aulas de educação física, por parte de seus praticantes, com e sem deficiência, apresenta o espaço-tempo de produção do conhecimento, como um lugar de construção e inventividade, em que se estabelecem possibilidades de criações individuais e, sobretudo, coletivas. Nessa perspectiva, o professor e as crianças são valorizados na condição de protagonistas do processo educativo.

Por isso é mais fértil produzir do que coletar dados e isso implica, para o pesquisador, fazer parte da aula, ser cúmplice, pois os praticantes, mais do que objetos de análise, são sujeitos protagonistas, atores e, também, autores das pesquisas (FERRAÇO, 2006; ALVES, 2008 apud KLIPPEL, 2013).

Para a produção de dados, realizamos observação participante com a sistematização em diário de campo realizado em 25 e 31 de março de 2014 e 07 de abril do mesmo ano, com documentos pedagógicos e registros icnográficos em uma escola pública de ensino fundamental.

Kramer (apud Klippel, 2013, p. 391) nos incentiva a enfrentar o desafio de pesquisar com as crianças no contexto concreto de intervenção pedagógica. Nesse sentido, destaca também que esse olhar sensível deve estar focado para “[...] entender a linguagem para além do pronunciado, compreender significados do corpo e seus movimentos".

Sob esse prisma, temos em mente que pensar em outras metodologias para pesquisar o protagonismo de crianças com transtorno opositivo desafiador nas aulas de Educação Física, pressupõe compreender/reconhecer a linguagem corporal como uma dimensão importante e fundamental dessas crianças em sua relação com o mundo.

\section{APRENDIZAGEM DO SUJEITO OPOSITOR NAS AULAS DE EDUCAÇÃO FÍSICA: UM OLHAR SÓCIO-HISTÓRICO}


Segundo Vigotski ${ }^{3}$ (2012), as funções superiores, na qual ocorre a aprendizagem, aparecem primeiro no nível social e, depois, no nível individual. Isto é, primeiro entre pessoas e, depois, no interior da criança. Todas as funções superiores originam-se das relações reais entre indivíduos. O aprendizado é necessariamente mediado por linguagem; portanto, sempre ocorre em situações de interação e muito antes da criança entrar na escola, portanto deve-se levar em consideração a história prévia do sujeito e a cultura na qual está inserido.

O elemento "histórico" funde-se com o cultural. Os instrumentos que o homem usa para dominar seu ambiente foram inventados e aperfeiçoados ao longo da história social do homem. A linguagem carrega consigo os conceitos generalizados, que são a fonte do conhecimento humano. Instrumentos culturais especiais, como a escrita e a aritmética, expandem enormemente os poderes do homem, tornando a sabedoria do passado analisável no presente e passível de aperfeiçoamento no futuro (VIGOTSKI, 2012, p.26).

Para o autor, o aprendizado escolar que pretende produzir algo novo no desenvolvimento do aprendiz deve considerar a zona proximal de desenvolvimento, que seria a distância entre o nível de desenvolvimento real, determinado pela solução independente de problemas, e o nível de desenvolvimento potencial, cuja solução de problemas se dá com orientação de um adulto (VIGOTSKI, 2007). Partindo dessa ótica Vigotskiana, que leva em conta os processos sociais de aprendizagem, poderemos focar a atuação do professor em sala de aula. A zona proximal de desenvolvimento e as oportunidades de propiciar aprendizado, as vozes que permeiam a aula e muitas outras considerações devem ser evocadas quando da elaboração de materiais de transposição didática. Para além disso, cabe ao professor se aproximar do aluno, no sentido de saber qual é a sua história e quais são os seus anseios.

Portanto, o emocional dá forma e estrutura à aprendizagem e à cognição, dando-lhe sentido. A ausência de uma estrutura emocional sólida pode influenciar, de maneira significativa, a evolução e o desenvolvimento da aprendizagem. Para um sujeito opositivo, que se irrita e tem o seu emocional abalado muito facilmente e que, dependendo do ambiente em que convive, e das pessoas que estão ao seu redor, o aprendizado poderá sofre prejuízos ou não.

Segundo Sampaio, "não é apenas um bom desenvolvimento cognitivo que implica uma boa aprendizagem. Fatores de ordem afetiva e social também influem de forma positiva ou negativa nesta aprendizagem" (SAMPAIO, 2011, p.17).

Portanto, o autocontrole das emoções determina a inteligência, o que nos leva a crer na premissa de que para o sujeito tenha autocontrole das emoções que o circundam diariamente, ele precisa ter um ambiente que o estruture e o organize, um ambiente de afeto. Nesse contexto, cabe ressaltar que "o afeto atua no início do processo de aprendizagem para canalizar a atenção, e no

\footnotetext{
${ }^{3}$ Optamos por essa grafia por se constituir uma transliteração mais próxima do português. Nas referências bibliográficas, no entanto, manteremos sempre como está escrito pelo autor.
} 
final para ajudar a memória no resgate das informações” (CUNHA, 2008, p.49). Em concordância com Cunha, Porto que afirma: "o afeto influencia a velocidade com que se constrói o conhecimento, pois, quando as pessoas se sentem seguras, aprendem com mais facilidade" (PORTO, 2011, p. 46). Nesse sentido, fizemos uma abordagem acerca dos desafios encontrados no processo de inclusão de um aluno com TOD nas aulas de educação física, em uma escola pública da Prefeitura Municipal de Vitória, Espírito Santo, durante o ano de 2014.

O primeiro desafio vem da família que sabemos que é o alicerce na construção do ser. Quando a família da criança com TOD vê a escola como uma válvula de escape e não como uma soma, nos deparamos com esse desafio que normalmente é recorrente nas escolas. Antes de a criança passar a ter sua vida escolar, ela vem sendo preparada por sua família, ou seja, as pessoas com quem a criança convive transmitem uma referência seja de valor positivo ou negativo. As primeiras relações educativas da criança são proporcionadas pela família seja no modelo de família pai e mãe, avó, tios ou outras configurações familiares, enfim, o círculo que a criança com TOD mais convive.

Nesse caminho, a convivência familiar faz significativa diferença nesse processo de construção da personalidade da criança com TOD, logo as famílias que se preocupam com seus filhos a superar as dificuldades que eles apresentam, estabelecem uma melhor relação no seio familiar:

O alicerce da construção das nossas emoções, do senso de "pertencer" e de ter valor, de ser amado ou rejeitado é transmitido de forma consciente ou inconsciente, com palavras, gestos ou ações. Esta transmissão é feita inicialmente pelos pais e reforçada pelos demais adultos com quem a criança vier a conviver (CASTRO, 2011, p. 40).

O segundo desafio é como os professores irão receber a criança com TOD, pois a dedicação é primordial para o desenvolvimento das várias habilidades do aluno. Dessa maneira, as suas potencialidades ganharam mais destaque que suas dificuldades, por isso os professores terão que construir com a criança um laço de afetividade para assim ter uma maior aproximação que possibilitam melhor observar as manifestações de interesse do aluno com esse diagnóstico.

São raros os educadores, sejam pais ou professores, que refutam a premissa de que as emoções e a aprendizagem estão interligadas. No ambiente familiar, escolar, comunitário, social e religioso, as relações vividas estão baseadas na afetividade e nos limites estabelecidos, sejam socialmente tratados ou culturalmente passados de uma geração para outra (CASTRO, 2011, p.28).

\section{MARCELO ${ }^{4}$ : ALUNO COM TRANSTORNO OPOSITIVO DESAFIADOR}

Marcelo é proveniente de uma família em que os pais trabalham e as duas irmãs mais velhas estudam em outra escola. Desenha bem e gosta muito de histórias em quadrinhos, atualmente faz

\footnotetext{
${ }^{4}$ Nome fictício para preservar a identidade do aluno.
} 
uso de medicação para o controle da ansiedade. Ele foi matriculado aos sete anos na escola onde trabalhamos, que é de ensino fundamental da Prefeitura de Vitória. O relatório vindo da educação infantil na qual frequentou, já tinha o laudo de TOD. Frequentou o segundo ano em 2009 e continuou até o ano de 2013, ano em que fizemos a nossa pesquisa com o TOD.

No princípio, Marcelo era uma criança muito agitada e agressiva. Ele, assim como as outras crianças, estranhou a nova escola e tinha dificuldade de ficar dentro da sala de aula. Por algum tempo, os pais buscavam Marcelo antes do horário da saída, porque ele sempre pedia para ir embora e ficava agressivo.

O horário de Marcelo na escola, foi modificado. Ele passou a ficar mais tempo com atendimento na sala de recursos para educação especial e nas aulas de artes. Não tinha um bom relacionamento com os colegas, as brigas e as discussões eram constantes e ele não frequentava muito as aulas de educação física. Com o passar dos anos, Marcelo aprendeu a ler, começou a frequentar o laboratório de informática e também a biblioteca.

Segundo a professora de educação especial da escola em sua avaliação final do ensino fundamental 1:

\begin{abstract}
Marcelo é uma criança muito desafiadora, que apresenta muitos problemas de relacionamento. Nas aulas de educação física fracassa bastante, pois não consegue trabalhar em equipe e não respeita regras. Nas aulas de artes, embora goste de desenhar, não apresenta avanços em seu traço e não consegue manipular o material junto com os outros colegas. Seu rendimento em relação ao conteúdo é bom, sabe ler, escrever e interpretar e consegue fazer operações simples de matemática.
\end{abstract}

Nesse caminho, no ano de 2013, Marcelo avançou para o $6^{\circ}$ ano do ensino fundamental, ano em que começamos o trabalho com ele, pois as nossas aulas eram ministradas para o ensino fundamental 2, ou seja, do sexto ao nono ano.

\title{
APROXIMAÇÕES ENTRE O PROFESSOR E O ALUNO COM TRANSTORNO OPOSITIVO DESAFIADOR
}

Para conseguirmos a aproximação com o sujeito opositivo, primeiramente, buscamos entender o que era o TOD. A compreensão desse transtorno é importante para que a escola e os professores tenham uma visão sistêmica do processo ensino-aprendizagem no qual este aluno está inserido, auxiliando o pleno desenvolvimento da aprendizagem das crianças que apresentam o transtorno e a sua inclusão e aceitação pela comunidade escolar. Os professores, ao se aproximarem, tornam-se elos importantíssimos para as crianças com TOD, pois é por meio das estratégias e do alto comprometimento com o ensino que o professor promove a autoestima dos alunos, estimulando a confiança e satisfação perante suas conquistas. 
Nossa aproximação demorou alguns dias, nos primeiros dias de aula, Marcelo ficava afastado e de longe, só observava o que estava acontecendo nas aulas. Com o tempo, fomos estabelecendo alguns momentos de diálogos, mas sempre afastado do grupo. Conversamos sobre a relação dele com a família, perguntamos o que ele fazia em casa, do que ele mais gostava na escola e porque ele não gostava de fazer educação física. Percebemos que a relação com a família é muito boa, ele cita muito o pai e as irmãs, sempre elogiando. Em casa gostava de assistir televisão e jogava vídeo game. Na escola, a sua preferência era o laboratório de informática para ficar jogando, e em relação às aulas de educação física, dizia que era muito chata e que os alunos da sua turma ficavam implicando muito, por isso não gostava.

Para Magallhães,

É válido ressaltar que a comunicação é um elemento decisivo para o processo da inclusão, ou seja, repetimos que a orientação básica é: Falem com elas! Trata-se de considerar a pessoa deficiente sujeito de sua aprendizagem. Neste sentido, a escola não é somente espaço de socialização, mas a instituição na qual as gerações mais jovens têm acesso ao conhecimento socialmente construído pela humanidade (MAGALHÃES, 2011, p.87).

Após a aproximação com Marcelo, fizemos uma conversa com a turma no momento em que ele não estava. Explicamos sobre o TOD e enfocamos a importância de melhorar a relação deles com Marcelo. Nesse sentido, Magalhães afirma que qualquer pessoa é única, singular na sua forma de ser e estar no mundo. Nossa identidade se constitui na medida em que construímos formas de intercâmbios sociais.

Só então começamos a pensar em práticas metodológicas que pudessem envolver todos os alunos da turma, incluindo Marcelo. Discutir sobre as propostas metodológicas para o trabalho pedagógico de criança com TOD não é uma tarefa tão simples. Implica compreender conceitos sobre a inclusão escolar para assim percebermos a extrema importância dessas propostas na dinâmica com a criança com o transtorno na escola. Segundo Carvalho (2007, p.107):

As práticas pedagógicas centradas na transmissão dos conhecimentos pelo professor, como profissional do ensino, desconsiderando-se os interesses e a bagagem vivencial dos alunos, certamente não tem dimensão política. Esta se instaura quando o professor se percebe e age como profissional da aprendizagem, estabelecendo relações dialógicas com seus alunos e valorizando todos os conhecimentos e experiências que trazem para a sala de aula. Com propriedade diz-se que o melhor e mais importante recurso para o professor é o próprio aprendiz.

Nesse contexto, repensamos as práticas pedagógicas direcionadas aos alunos com TOD e registramos uma proposta pedagógica no programa de ensino para o sexto ano do ensino fundamental para o primeiro trimestre de 2014 que ocorreu entre os dias 03 de fevereiro a 16 de maio do mesmo ano. A proposta pedagógica foi assim delineada:

Proposta pedagógica: cultura corporal de movimento - confecção de brinquedos, brincadeiras. Temas transversais: meio ambiente e reciclagem. 
Estratégias de ensino:

- Dialogar constantemente com os alunos;

- Realizar atividades a partir de sugestões dos alunos;

- Planejar e confeccionar brinquedos;

- Realizar atividades que enfatizam a importância de se preservar a natureza.

Marcelo e os alunos do sexto ano nos ajudaram a pensar nas aulas de forma com que todos participassem. Começamos com uma conversa onde os alunos diziam quais eram as atividades físicas que mais gostavam e quais eram os brinquedos favoritos. A maioria respondeu que gostava de futebol e de queimada e dentre os brinquedos escolhidos, a preferência foi pelos jogos eletrônicos. Em relação aos jogos pré-desportivos e aos esportivos, Vigotski afirma que:

Os jogos esportivos (não somente os esportes atléticos, mas também outros jogos que podem ser ganhos ou perdidos), são, com muita frequência, acompanhados do desprazer, quando o resultado é desfavorável para a criança (VIGOTSKI, 2007, p. 107).

Para um sujeito opositivo, os jogos esportivos podem dificultar o seu aprendizado, pois vimos que Marcelo tinha dificuldade de aceitar as regras e jogar em equipe. Dessa forma, não pretendíamos trabalhar com jogos esportivos no início do ano. Quanto aos brinquedos, sugerimos aos alunos que fossem confeccionados alguns brinquedos com materiais recicláveis, assim aproveitaríamos para abordar a questão do lixo e meio ambiente que era o tema da mostra cultural daquele ano e também usariam a imaginação na montagem dos brinquedos.

Na fala de Vigotski,

A atividade de imaginação criadora é muito complexa e depende de uma série de diferentes fatores. Por isso, é completamente compreensível que essa atividade não possa ser igual na criança e no adulto, uma vez que todos esses fatores adquirem formas distintas em diversas épocas da infância (VIGOTSKI, 2009, p. 43).

Sabemos que a imaginação depende da experiência que a criança traz culturalmente. Dessa forma, buscamos compreender quais eram as experiências que Marcelo e os alunos do sexto ano traziam na medida em que usassem a imaginação para a confecção dos brinquedos.

\section{APROXIMAÇÃO COM AS BRINCADEIRAS E COM A TURMA}

\section{Confecção de brinquedos}

Os materiais usados foram: copos descartáveis, garrafas pet, barbante, latas de leite, corda de varal e papéis. Ao usarem a imaginação, os brinquedos feitos pelos alunos foram:

- Telefone com fio - Material: copos descartáveis e barbantes.

- Bilboquê - Material: garrafa pet, barbante e papel.

- Vai e vem - Material: garrafa pet e corda de varal.

- Pé na lata - Material: latas de leite e barbante. 
Para Chicon (2004, p.23), “o brinquedo tem uma dimensão material, cultural e técnica. É o estimulante material para fazer fluir o imaginário infantil”. Dessa forma, as metodologias diferenciadas que proporcionam o aprendizado de todos os alunos, ampliam também, o trabalho pedagógico com a criança com TOD, pois possibilitará caminhos e estratégias para atender as necessidades da criança com esse diagnóstico, principalmente em relação ao ensino aprendizagem, na interação com seus pares, que é uma das suas maiores dificuldades.

Ao distribuirmos os materiais, percebemos que na medida em que foram criados os brinquedos, Marcelo demonstrou um interesse muito grande e sempre pedia que nós ajudássemos a confeccionar o seu brinquedo. O primeiro brinquedo que Marcelo pegou foi o telefone com fio e em seguida, chamou um colega de sala e foi brincar. Neste momento, o brinquedo confeccionado contribuiu para a interação de Marcelo com os outros sujeitos, no mesmo espaço-tempo de aula. Subindo nas grades da quadra, Marcelo usou ainda a imaginação para dizer que ali era a torre onde ficava a antena do telefone móvel e que ele teria que consertar, pois estava tendo muita interferência e as pessoas não estavam conseguindo se comunicar direito. O interesse de Marcelo aumentou e ele, com a ajuda dos colegas, terminaram de confeccionar os outros brinquedos.

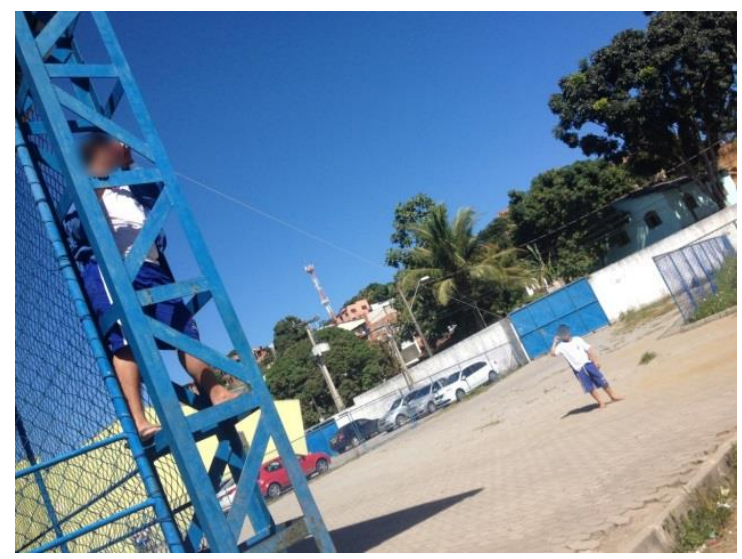

Figura 1 - Marcelo na "torre do telefone móvel”.

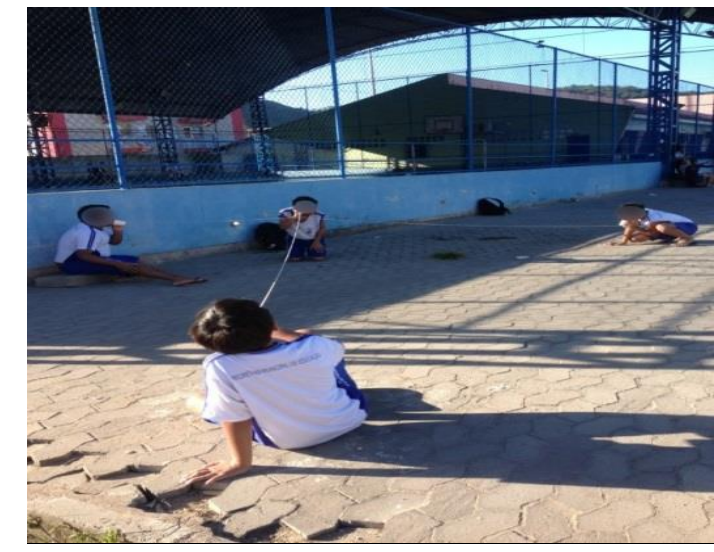

Figura 2 - Brincadeira do telefone com fio.

Nesse contexto, é importante trazer a fala de Vigotski. O autor afirma que: 
A brincadeira, que referimos como melhor mecanismo educativo do instinto, é ao mesmo tempo a melhor forma de organização do comportamento emocional. A brincadeira da criança é sempre emocional, desperta nela sentimentos fortes e nítidos, mas a ensina a seguir cegamente as emoções, a combiná-las com as regras do jogo e o seu objetivo final (VIGOTSKI, 2010, p.147).

Assim, a brincadeira constitui, para Marcelo, uma das formas de se relacionar com os colegas nas aulas de educação física, sem agressividade ou discussões e sem se colocar contrário as regras, pois as regras nesse momento eram confeccionar o brinquedo e brincar. E assim ele participou da confecção e das brincadeiras dos outros brinquedos citados, alcançando assim, o nosso objetivo de aproximação do Marcelo conosco e com a turma.

\section{Participação efetiva nas aulas de educação física}

Na medida em que os objetivos de aproximação e participação nas aulas de educação física foram alcançados, avançamos no conteúdo. O próximo passo era fazer uma discussão sobre o meio ambiente e trazer os problemas que afetam a natureza. Dentre os problemas citados, enfatizamos a poluição dos rios. Perguntamos aos alunos quais atividades físicas poderiam ser feitas na natureza. Eles elencaram como principais atividades a trilha, a tirolesa, a escalada, a corda bamba, dentre outras. Marcelo ouvia atento junto do grupo e participava de forma ainda tímida.

O trabalho desenvolvido foi resultado de muitas observações do comportamento de Marcelo na escola, para assim ter maior chance de desenvolver um trabalho que despertasse a sua curiosidade e o seu interesse em aprender. Por isso, é importante dizer que os recursos empregados nesse processo têm grande responsabilidade em construir melhores caminhos para o aprendizado da criança com TOD e a construção de laços afetivos com seus colegas.

Essas propostas metodológicas supracitadas para o trabalho pedagógico com a criança com TOD ajudam no processo de ensino-aprendizagem, no seu desenvolvimento cognitivo e na construção do pensamento abstrato. São metodologias que podem ser adaptadas, transformadas e (re)criadas de acordo com a criatividade da professor(a) e do que os alunos demonstram interesse em aprender.

Das atividades citadas, escolhemos a corda bamba que consiste duas cordas paralelas, uma alta e outra baixa onde os alunos devem atravessar segurando a corda acima da cabeça e apoiando os pés na corda próxima ao chão. Nessa atividade, obtivemos uma participação efetiva de todos os alunos do sexto ano. 


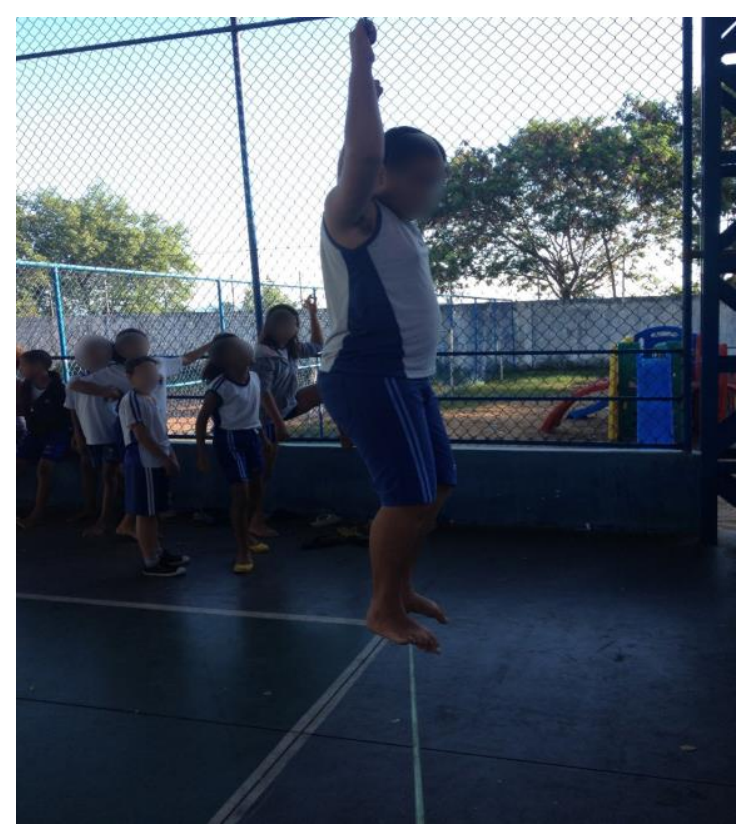

Figura 3 - Marcelo na Corda bamba.

\section{Algumas tecituras}

Diante do estudo e da prática realizada com um aluno com TOD, é importante dizer que essa pesquisa proporcionou uma reflexão ampla acerca das dificuldades de inclusão escolar da criança com TOD e contribuiu para a superação dos desafios da inclusão nas aulas de educação física.

Enfatizamos a necessidade de propostas metodológicas para o trabalho pedagógico com criança com TOD, em que cada criança possa ser vista como um sujeito singular, único em sua constituição sócio-histórica. Por isso nós, professores, devemos observar quais atividades a criança aprecia realizar dentro do contexto escolar que está inserida.

Assim, assumimos o entendimento de que temos que respeitar e aprender a proporcionar melhores caminhos de ensino e aprendizagem para crianças com TOD nas aulas de educação física. Nesse sentido, ao nos aproximarmos dos nossos alunos, devemos ter uma escuta sensível, como nos conta Orrú:

\footnotetext{
A escuta sensível supõe uma inversão de atenção. Antes de situar uma pessoa em seu lugar, comecemos por reconhecê-la em seu ser, em sua qualidade de pessoa complexa, dotada de liberdade e de imaginação criadora. É importante conhecermos o contexto em que a pessoa está inserida, contudo não podemos enxergar o outro como ser inerte e impossibilitado de mudanças. Todo ser humano tem uma capacidade criadora e imaginária que, na maioria das situações, é inibida em função de vários fatores, desde os sociais até os econômicos (ORRÚ, 2010, p.233).
}

Nesse sentido, a escuta sensível valoriza o sujeito e nos mostra que existem várias possibilidades para a inclusão de alunos com deficiência e, no nosso caso, de um aluno com TOD nas aulas de educação física. 
Acreditamos que essa pesquisa pode possibilitar muitas reflexões a respeito do assunto e incentivar outras pesquisas com relação à prática da inclusão escolar da criança com TOD, além de possibilitar mais informações para aqueles que também se identificam com a prática da inclusão escolar.

Em suma, nosso pensamento acerca da inclusão escolar do sujeito com TOD converge com o olhar de Freitas (2013, p.17). Nas falas do autor:

\begin{abstract}
Desenvolver uma "atitude inclusiva" não significa apenas conduzir sujeitos para dentro de disciplinas e fronteiras acadêmicas. O que está em questão é enxergar o outro sem reduzi-lo às marcas de seu corpo; às mutilações que sofreu ou as ineficiências que seu organismo expõe quando comparado a outro.
\end{abstract}

\title{
Referências
}

ABREU, J. R. G. Inclusão na Educação Física Escolar: Abrindo Novas Trilhas. Dissertação de Mestrado - Programa de Pós-Graduação em Educação Física, Universidade Federal do Espírito Santo, 2011.

CARMO, A. A. do. Inclusão escolar e a educação física: que movimentos são estes? Revista Integração, Brasília, ano 14, p.6-13, mar. 2002. Edição especial: Educação Física Adaptada.

CARVALHO, R.E. Removendo barreiras para a aprendizagem: educação inclusiva. Porto Alegre: Mediação, 2007.

CASTRO, E. Afetividade e limites: uma parceria entre família e escola/ Edileide Castro - 3. ed. - Rio de Janeiro: Wak Editora, 2011.

CHICON, J. F. Inclusão na Educação física escolar: construindo caminhos. Tese (Doutorado em Educação) - Programa de pós- Graduação em Educação, Faculdade de Educação, Universidade de São Paulo. São Paulo, 2005.

CHICON, J. F. Jogo, mediação pedagógica e inclusão: a práxis pedagógica. Vitória: ADUFES, 2004.

CUNHA, E. Afeto e aprendizagem: amorosidade e saber na prática pedagógica. Rio de Janeiro: Wak Ed., 2008.

FREITAS, M. C. de. O aluno incluído na educação básica: avaliação e permanência. São Paulo: Cortez, 2013.

KAPLAN, H I.; SADOCK J.; GREB. A. Compêndio de Psiquiatria: Ciências do comportamento e Psiquiatria Clínica. 7. ed. 3. reimpressão. Porto Alegre: Artmed, 1997.

KLIPPEL, M. V. O jogo na Educação Física Infantil: usos e apropriações em uma CMEI de Vitória/ES. Dissertação de Mestrado - Programa de Pós-Graduação em Educação Física, da Universidade Federal do Espírito Santo, 2013. 
LUISELLI, J. K. Características clínicas e tratamento do transtorno desafiador de oposição. In: V. E. Caballo e M. Simon (Orgs.). Manual de psicologia clínica infantil e do adolescente: Transtornos específicos. São Paulo: Santos, 2005. (p. 39- 55).

MAGALHÃES, R. C. B. P. (Org.) Educação inclusiva e escolarização: política e formação docente. Brasília: Liber Livro, 2011.

MONDONI, S. M. PITLUIK, R. Transtorno desafiador de oposição (TDO). Disponível em: http://www.mentalhelp.com/sua-saude/perguntas-e-respostas/tourette-tiques-e-cacoetes. Acessado em 23 de outubro de 2014.

ORRÙ, S. E. (org.) para além da educação especial: avanços e desafios de uma educação inclusiva. . Rio de Janeiro: Wak Ed., 2010.

PORTO, O. Bases da Psicopedagogia: diagnóstico e intervenção nos problemas de aprendizagem. $5^{\circ}$ Ed. Rio de Janeiro: Wak Ed., 2011.

RELVAS, M. P. Neurociência e transtornos de aprendizagem: as múltiplas eficiências para uma educação inclusiva. 4 ed. Rio de Janeiro: Wak Ed., 2010.

SAMPAIO, S. Dificuldades de aprendizagem: a psicopedagogia na relação sujeito, família e escola. $3^{\circ}$ Ed. Rio de Janeiro: Wak, 2011.

SOBRINHO, F. P. N. Inclusão educacional: Pesquisa e interfaces. Rio de Janeiro: Ed.Livre Expressão. 2003.

TEIXEIRA, G. Terapêutica medicamentosa no transtorno desafiador opositivo. Arquivos brasileiros de psiquiatria, neurologia e medicina legal - vol. $100 \mathrm{n}^{\mathbf{0}}$ 02; abr/maio/jun 2006. Disponível em: http://www.comportamentoinfantil.com/tdo1.pdf. Acessado em 17 de novembro de 2014.

URICOCHEA, A. S. Diversidade e Inclusão: A vivência de um novo paradigma. Disponível em < www.moodle.ufba.br/inclusão.doc $>$. Acesso em 15 dez. 2014.

VICTOR, S. L.; DRAGO, R.; PANTALEÃO, E.(ORGS.). Educação especial: indícios, registros e práticas de inclusão. São Carlos: Pedro \& João Editores, 2013.

VIGOTSKI, L. S. A Formação Social da Mente: o desenvolvimento dos processos psicológicos superiores. $7^{\circ}$ Ed. São Paulo: Martins Fontes, 2007.

Estudos sobre a história do comportamento: o macaco, o primitivo e a criança. Porto Alegre: Artes Médicas, 1996.

Imaginação e criação na infância. São Paulo: Ática, 2009.

2012.

Linguagem, Desenvolvimento e Aprendizagem. $12^{\circ}$ edição-São Paulo: Ícone,

Obras escogidas V - Fundamentos de Defectologia. Madri: Visor, 1997.

Psicologia pedagógica. . $3^{\circ}$ Ed. São Paulo: Martins Fontes, 2010. 
Recebido em: 02.03.2015

Aceito em: 23.07.2017 